\title{
La insignificancia del hombre frente a los animales en los cuentos de Horacio Quiroga
}

\author{
A insignificância do homem frente aos animais nos contos \\ de Horacio Quiroga
}

\section{Bárbara Bianca Batisti}

\section{Cátia Hentges}

Universidade do Vale do Taquari - UNIVATES - Lajeado - Rio Grande do Sul - Brasil

\begin{abstract}
Resumen: El hombre se cree más inteligente que los animales porque es capaz de pensar y reflexionar, pero los animales, la naturaleza, también son muy sabios, utilizan su sabiduría para engañar y destruir al hombre. La creencia del hombre de que es mucho más inteligente que los animales hace que él esté más vulnerable a los ataques silenciosos y poderosos de los animales y de la naturaleza. En los cuentos El desierto y La miel silvestre, de Horacio Quiroga, es posible percibir la insignificancia del hombre frente a los animales, que son muy astutos en su venganza contra los humanos, y como su venganza es simple, nada de muy fenomenal, pero es perfecta. De ese modo serán analizados dos cuentos de Quiroga en que la supremacía de los animales sobre el hombre es visible, ya que su venganza es silenciosa y fatal. Además, será observado el significado que esta reprensión produjo en el cuento y como puede ser interpretada y relacionada con el contexto actual.
\end{abstract}

Palabras-clave: Horacio Quiroga; cuentos; hombre versus animales.

Resumo: O homem crê ser mais inteligente que os animais porque é capaz de pensar e refletir, mas os animais e a natureza também são sábios, utilizam sua sabedoria para enganar e destruir o homem. A crença do homem ser muito mais inteligente que os animais faz com que ele esteja mais vulnerável aos ataques silenciosos e poderosos dos animais e da natureza. Nos contos El desierto e La miel silvestre, de Horacio Quiroga, é possível perceber a insignificância do homem frente aos animais, que são muito astutos em sua vingança contra os humanos, simples, silenciosa, mas perfeita. Desse modo, serão analisados dois contos de Quiroga em que a supremacia dos animais sobre o homem é visível, já que sua vingança é soturna e fatal. Além disso, será observado o significado que esta repreensão traz ao conto e como pode ser interpretada e relacionada com o contexto atual.

Palavras-chave: Horacio Quiroga; contos; homem versus animais. 


\section{Introducción}

Desde los tiempos más remotos, el hombre piensa estar por delante de los animales por su capacidad de pensar, reflexionar, por su inteligencia y sabiduría. Él cree que es superior y que tiene poder sobre los otros animales, ya que posee consciencia de sus actos y también tiene la capacidad de hablar y persuadir a los demás.

A partir de este estado de superioridad, el humano actúa como si fuera el dueño de las cosas que hay en la naturaleza, explorando las matas y sacrificando los animales. Conforme Watts (1992, p.17), el hombre siempre se consideró "el cabeza", el señor de la naturaleza y por ello explota los recursos de la tierra, manejando el universo sin la más mínima preocupación.

Sin embargo, toda esta creencia, que perdura a siglos, no pasa de una ilusión. Al sentirse amenazada, la naturaleza también busca fuerzas para librarse del humano que intenta dominarla. Una prueba de este contraataque puede ser verificada claramente en los cuentos del escritor uruguayo Horacio Quiroga. Algunos de sus personajes mueren, una vez que no logran salvarse del ataque silencioso de pequeños animales.

Los animales no piensan hacer malo a los otros animales y a los hombres, ellos actúan en su defensa cuando se sienten amenazados, solo para sobrevivir. Pero el hombre no actúa siempre con la misma intención, muchas veces mata a los animales para sacar provecho de su piel, su carne, o simplemente para ver su sufrimiento, son pocas las situaciones en las que el ser humano mata un miembro de la naturaleza para protegerse,

"La vida en la naturaleza es esencialmente equilibrio, ningún animal mata por placer, sino por su necesaria supervivencia en busca de alimento. Sólo el hombre mata por el placer de matar; sólo el hombre provoca dolor a otros animales para regocijarse con el sufrimiento ajeno." (Revista Pelo Pico Pata № 49)

El presente trabajo busca explorar, en dos narrativas de Horacio Quiroga, situaciones en que el hombre se torna insignificante frente a los animales que lo cercan. A partir de estas circunstancias, incluso fue posible reflexionar sobre el significado de estos acontecimientos dentro de los cuentos, y también en el contexto actual, sobre el valor que es dado a estos pequeños animales, que parecen ser inofensivos por su despreciable tamaño pero tienen el poder de derribar el más sabio de los seres.

\section{La relación de Horacio Quiroga con la selva y los animales}

Horacio Quiroga nació en Salto, ciudad uruguaya, en 31 de diciembre de 1878. A lo largo de su vida, presenció una serie de muertes violentas, como la de su padre, que se disparó un tiro accidental y fatal, años más tarde el suicidio de su padrastro, la fiebre que llevó dos de sus hermanas, el tiro que Quiroga disparó accidentalmente y acabó con la vida de su mejor amigo y la depresión que causó el suicidio de su primera mujer. Esta secuencia de muertes, sin duda, va a reflejarse a lo largo de sus obras.

Quiroga vivió hasta 1912 entre Montevideo, Buenos Aires y París. Tras sufrir desilusiones amorosas, económicas y literarias, huye de estos grandes centros para vivir en la selva. Diez considera que el escritor era

"un hombre que parece, al mismo tiempo, vivir buscándose a sí mismo e intentando fugarse de sí en todo instante, como si recubriera con mil máscaras el rostro verdadero... [y que] hunde su vida en la selva para encontrarse a sí mismo y la hunde también para olvidarse de sí." Diez (2000, p.76)

Vivió en Misiones durante mucho tiempo, buscando su raíz y su propia identidad, lo que parecía imposible encontrar dentro de la urbanización civilizadora donde estaba anteriormente. Según Canfield (1990, p.31), instalado en Misiones Quiroga producía todo lo que necesitaba para sobrevivir en la selva y no adquiría nada de la ciudad, ni ropa, tampoco herramientas para su trabajo en la tierra. La selva fue una nueva manera de vivir. La necesidad de hacer todo para sobrevivir, las dificultades existentes en vivir en un espacio donde no se tiene nada y es necesario construir todo, fueron para Quiroga una 
terapia, haciendo un bien indispensable para su mente.

Mientras la mayoría de los escritores americanos aspiraban a simular de manera correcta las modas literarias venidas de Europa, Quiroga hacía un enorme esfuerzo para inventar un lenguaje selvático de América. De este modo, oye la voz de la naturaleza e intenta reproducirla. Siguiendo esta línea, es posible pensar que, para el escritor, "la selva se retrata para trascenderse, se proyecta más allá de sí misma, como encarnación de una condición humana original, moralmente superior" (Canfield, 1997, p.1362).

Reconociendo la naturaleza como superior a los hombres, Quiroga muestra en sus cuentos que es de ella que el hombre surge y también para ella que volverá y, por más que busque esforzarse, esta lucha es ineficaz, pues el hombre no tiene el comando sobre la vida. De este modo, los personajes viven con la presencia del pesimismo y del fatalismo, no logrando convivir pacíficamente con su entorno, acabando por ser atacados y destruidos por este medio.

Además, para este autor, la selva no era solo un tema o un símbolo, sino también una escuela de indagación existencial. La búsqueda por las raíces y por la definición de su propia identidad son obsesiones constantes del hispanoamericano, seguramente a causa de la violenta colisión entre los españoles y los indígenas. Por ello, Canfield (1997) afirma que la nostalgia de las raíces que tiene Quiroga es la nostalgia del hombre americano brutalmente separado de sus orígenes. Su regreso volver a convivir o a entrar en contacto con la naturaleza - no era una tarea fácil; elegir la selva como sitio privilegiado del origen, como su matriz, no era nada previsible. Sobre ese regreso de la ciudad, Canfield apunta que

"[...] al regresar a su lugar de origen, la selva, el hombre ya corrompido contamina también las relaciones entre animales y hombres, o entre salvajes y civilizados, 0 entre desposeídos de la tierra y prepotentes apoderados. La denuncia social vinculada a la temática de la selva está presente en la obra de Quiroga en varios cuentos." (Canfield, 1997, p.1367)
La temática de la selva empieza a presentarse en los cuentos de Quiroga después de sus viajes a Misiones (1903) y al Chaco (1904), de forma tímida en "La serpiente cascabel", "Las rayas" y "La insolación", para pasar a ser predominante a partir de 1909, fecha de su matrimonio y de su establecimiento en Misiones. Al inicio, la relación entre el hombre y los animales es armónica, pero tras un tiempo, según Canfiend (1997, p.1366), lo que queda de la antigua amistad entre el hombre y la fiera son casos aislados en un contexto abominable de explotación del hombre por el hombre y de insensata destrucción de los recursos naturales.

Por ser una madre con el poder de dar y de sacar la vida, la selva tiene fuerzas para hacer que de ella brote una vida, alimentarla y cultivarla, pero también tiene fuerzas suficientes para hacer brotar la muerte, ayudando a bien morir. El contacto con la selva puede renovar el ánimo de las personas o preparar para la muerte. Para reforzar esta postura de auto preservación, Rodríguez (2013, p.12) afirmó que

"los personajes de estas novelas o cuentos de la selva caminan con la muerte, consciente o inconscientemente se dirigen hacia ella y en muchos casos la buscan, algunos inclusive invocan su presencia casi como un bálsamo en medio de la ferocidad de la selva."

Ambos los cuentos analizados en este trabajo presentan personajes que volvieron para la selva y que fueron muertos por animales presentes en ella, en situaciones de embestidas contra posibles amenazas de los humanos.

\section{El poder de los animales y la insignificancia del hombre}

Horacio Quiroga, en muchas de sus obras, abordó el gran tema misionero, una vez que vivía en la selva, respetaba la naturaleza y reconocía la peligrosidad de los animales que habitaban este sitio. Para César Tiempo (1970, p.12), fue con Quiroga que la selva pasó a tener existencia literaria. Fue a partir del momento en que él puso sus manos y sus ojos sobre ella que empezó a existir, a temblar y a tener voz. Además, también en relación a su postura ante 
la naturaleza, en Quiroga (1997, p. 1153) se encuentra que

"El objeto literario es el animal recortado en su ambiente, descripto en sus costumbres con la minucia imparcialidad del naturalista y la sabrosa simpatía del conterráneo. [...] hay una actitud de respecto comprensivo frente a los animales, aun cuando se hallen en su momento de mayor peligrosidad. Tal, por ejemplo, la escena en el fondo del pozo con la yararacusú, donde Quiroga llega entablar una oposición entre la moral de la víbora y la de él mismo. [...] La inferioridad ética del hombre frente al animal se contempla en repetidas alusiones a la incompetencia humana cuando se trata de preservar la vida del animal 0 alimentarlo."

Pensando en el hombre como alguien que no sabe convivir en armonía con los animales, para Canfield (1997, p.1362) Quiroga compara ese humano que busca la vida de la selva con una especie de Robinson que persigue una isla de vida más verdadera. Esta selva que aísla y que tiene extraordinarios poderes terapéuticos es también la que está siendo amenazada por la civilización, por la ambición de dominio del hombre, su gran destructor.

Ese gran destructor sufre las consecuencias pues, según Rodríguez (2013, p.27), hay un límite señalado en la naturaleza entre dominar y usufructuar o ser presa y parecer engullido desde las entrañas y el espíritu hasta la carne, los huesos y la piel. En los cuentos de Quiroga, la segunda opción es la que se encuentra con evidencia. La madre naturaleza se auto preserva reaccionando a través de sus animales que, literalmente, devoran la carne humana. Rodríguez aún afirma que

“...la naturaleza revela las fragilidades del hombre, cuando éste, en medio de tormentosos y calientes miasmas, desnuda su ser - sus miedos, sus ambiciones frustradas y se reconoce a sí mismo como un irrisorio adversario que no puede más que someterse ante la bestia verde, esperando una inexistente misericordia." (Rodríguez, 2013, p.102)

En vano, los humanos después de explotar la naturaleza aún esperan de ella su misericordia. Es un confronto donde uno es adversario del otro y no hay piedad de ninguna de las partes. Mientras el hombre busca una vida mejor haciéndose dueño de lo que hay en la selva, esta contrataca en la figura de los animales, demostrando quien es más fuerte.

\subsection{Los parásitos infernales en el cuento EI desierto}

En el cuento El desierto, Subercasaux es viudo y padre de dos hijos. En la primera parte de la narración es descripta la vida de este padre y el modo como educaba sus hijos, una chica de seis años y un chico de cinco. Vivían en Misiones, un escenario de selva en Argentina.

Como no había una mujer en la casa para limpiar y cocinar, Subercasaux buscaba criadas para hacer esos servicios. Sin embargo, ellas no se quedaban allí por mucho tiempo a causa del carácter muy duro del patrón. De este modo, Subercasaux tenía que hacerse las tareas domésticas. Cocinaba, cosía las ropas de los hijos, pero barrer era la única tarea que se recusaba hacer. Para él, era una tarea circular y exclusivamente femenina.

Por dejar de remover la suciedad que había alrededor de la casa, la arena se convirtió en un criadero de piques, que se proliferaron tanto que atacaban a los chicos.

"En esa suelta arena sin remover, convertida en laboratorio de cultivo por el tiempo cruzado de lluvias y sol ardiente, los piques se propagaron de tal modo que se los veía trepar por los pies descalzos de los chicos. Subercasaux, aunque siempre de stromboot, pagaba pesado tributo a los piques. $Y$ rengo casi siempre, debía pasar una hora entera después de almorzar con los pies de su chico entre las manos, en el corredor y salpicado de Iluvia o en el patio cegado por el sol. Cuando concluía con el varoncito, le tocaba el turno a sí mismo; y al incorporarse por fin, curvaturado, el nene lo llamaba porque tres nuevos piques le habían taladrado a medias la piel de los pies." (QUIROGA, 1997, p.496)

Al inicio, aquello no les perturbaba tanto. El narrador llega a apuntar que los piques son mucho más inofensivos que las víboras, pero esto estaba tornándose un caos, pues ellos estaban perforando la carne y poniendo sus huevos allí. Utilizaban botas y este accesorio les parecía la máxima protección contra los ataques, pero esto no pasó de un engaño. Al fin, los piques no eran tan insignificantes como los juzgaban.

Subercasaux no lograba deshacerse de uno que tenía en el dedo del pie. El dolor era muy grande y ya no podía más dormir. Sentía mucho frío y no 
conseguía calentarse a causa de la fiebre. Incluso, a veces, llegaba a desvariar pensando que todo aquello era un sueño y que necesitaba pararlo para cuidar de sus hijos. Se quedaba en la cama y pensaba una manera de encontrar la cura.

"¡Quedar en cama hasta las diez, siquiera!... En cuatro horas pasaría la fiebre, y la misma cintura no le dolería tanto... ¿Qué necesitaba, en suma, para curarse? Un poco de descanso, nada más. Él mismo se lo había repetido diez veces. [...] ¡Qué bien estaba así! ¡Quedar uno, diez, cien días sin moverse! [...] ¡Qué gozo de hallarse bien caliente, por fin, en la cama, sin ninguna, ninguna preocupación!... ¿Cuándo, en qué época anterior había él soñado estar enfermo, con una preocupación terrible?... ¡Qué zonzo había sido!..." (QUIROGA, 1997, p.500)

Además de permanecer en la cama, Subercasaux se preocupaba mucho con la leche de los niños, como irían conseguirla para sobrevivir si él muriera. Incluso pensaba muchas veces en beberlo, ya que estaba enfermo y no podía levantarse para cocinar algo para comer.

"Sin darse cuenta precisa de lo que había hecho esa tarde, Subercasaux vio llegar la noche con hondo deleite. Recordaba, sí, que el muchacho no había traído esa tarde la leche, y que él había mirado un largo rato su herida, sin percibir en ella nada de particular. Cayó en la cama sin desvestirse siquiera, y en breve tiempo la fiebre lo arrebató otra vez. El muchacho que no había llegado con la leche... ¡Qué locura!" (QUIROGA, 1997, p.501)

La leche, bebida que se explota de los animales, puede ser relacionada al contraataque hecho a través de los piques. Subercasaux es una amenaza para la selva y esta intervine con la ayuda de los piques, buscando expulsar ellos de allí, del territorio que es suyo. Otra evidencia de esta relación es que la chica no fue atacada, solamente el padre y su hijo. Pensando de esta forma, los que demostraban peligro a la naturaleza eran los hombres y no las mujeres.

"La mujercita parecía inmune, por ventura; no había modo de que sus uñitas tentaran a los piques, de diez de los cuales siete correspondían de derecho al nene y sólo tres a su padre." (QUIROGA, 1997, p.496)

Por fin, tras sacar sus botas y quedarse con la herida en el barro, Subercasaux sufre de una infección generalizada y no logra sobrevivir. Llama sus hijos y los prepara para su muerte.

\subsection{La dulce venganza en el cuento La miel silvestre}

Benincasa es un contador que decide volver para visitar sus orígenes rurales en el cuento La miel silvestre. Se aventura por la selva sin ninguna instrucción y sin compañía, llevando solamente sus famosos stromboot, creyendo que el calzado lo protegería de todos los peligros.

"Apenas salido de Corrientes había calzado sus recias botas, pues los yacarés de la orilla calentaban ya el paisaje. Mas a pesar de ello el contador público cuidaba mucho de su calzado, evitándole arañazos y sucios contactos." (QUIROGA, 1997, p.123)

En el inicio del cuento, el narrador apunta que el bosque era una fuente de libertad con sus peligros encantadores. De este modo, Benincasa pone sus botas para protegerse de estos peligros y las cuida tanto como si fueran el bien más precioso que tuviera, las cuidaba más que a su propia vida.

En uno de estos días en la selva, su padrino lo despertó y, al levantarse, Benincasa fue sorprendido por la corrección. El padrino le explicó que son pequeñas, negras y brillantes. Devoran todo lo que encuentran, dejando los huesos por el suelo:

"Avanzan devorando todo lo que encuentran a su paso: arañas, grillos, alacranes, sapos, víboras, y a cuanto ser no puede resistirles. No hay animal, por grande y fuerte que sea, que no huya de ellas. Su entrada en una casa supone la exterminación absoluta de todo ser viviente, pues no hay rincón ni agujero profundo donde no se precipite el río devorador. Los perros aúllan, los bueyes mugen, y es forzoso abandonarles la casa, a trueque de ser roído en diez horas hasta el esqueleto." (QUIROGA, 1997, p.124)

En el día siguiente, Benincasa agarró un machete y se fue por la selva adentro. Creía que esta herramienta sería muy útil, más que un fusil, por comprender el contexto. Un zumbido le llamó la atención y percibió que, dentro de un tronco hueco, había diminutas abejas. Se acercó y vio que había miel. Lleno de gula, sacó las bolsitas del tronco y, 
golosamente, empezó a comer la miel. Las abejas no tenían aguijón y eso facilitó el robo.

"La suerte quiso que mientras el ladrón acercaba cautelosamente la hojarasca húmeda, cuatro o cinco abejas se posaran en su mano, sin picarlo. Benincasa cogió una enseguida, y oprimiéndole el abdomen constató que no tenía aguijón. Su saliva, ya liviana, se clarificó en melífica abundancia. ¡Maravillosos y buenos animalitos!" (QUIROGA, 1997, p.125)

El propio narrador, en este trecho, señala Benincasa como un ladrón, que devora la miel por gula, engullendo en un piscar de ojos la miel de cinco colmenas, sin pensar en el trabajo arduo y demorado que ellas tuvieron. Para vengarse de este ladrón, la miel, por ser silvestre y tener un fuerte olor de eucalipto, tenía propiedades paralizantes. Su falta de experiencia hizo con que se engañara cuanto al sabor característico. El propio nombre silvestre significa algo oculto e inicuo, presente en ambientes como este del cuento.

\begin{abstract}
“...en la selva-muerte, todo elemento desconocido irradia peligro mortal. El inexplicable pero agradable sabor mentolado de la miel, que dicho sea de paso es oscura y no color ámbar como usualmente es este espeso líquido, resulta ser un aderezo funesto para Benincasa, quien es incapaz de reconocer el peligro en su extraño sabor y color." (RODRIGUEZ, 2013, p.130)
\end{abstract}

Tras comerlo, Benincasa sintió que su cuerpo hormigueaba, como si hubiera corrección en su cuerpo. Sentía miedo de no conseguir moverse y morir allí, solo en la selva. Se encontraba paralizado y una invencible somnolencia se apoderaba de él. Aterrorizado, sintió que las hormigas vistas ayer empezaban a subirle por las piernas, llegando a entrar por su calzoncillo.

"Tuvo aún fuerzas para arrancarse a ese último espanto, y de pronto lanzó un grito, un verdadero alarido en que la voz del hombre recobra la tonalidad del niño aterrado: por sus piernas trepaba un precipitado río de hormigas negras. Alrededor de él la corrección devoradora oscurecía el suelo, y el contador sintió por bajo del calzoncillo el río de hormigas carnívoras que subían." (QUIROGA, 1997, p.126)

Por el hecho de las hormigas adentraren en su calzoncillo, es posible interpretar que la fuerza y la virilidad del hombre se hace nula frente a estos animales. De hombre valiente se convirtió en un niño con miedoun Además, el propio nombre de las hormigas ya explica todo: corrección. No eran de un tipo cualquiera, vinieron para corregir algo de errado que por allí pasó. Esto no era su lugar, estaba tomando algo que no era suyo y no se sentía culpable:

"Su destino final tiene mucho más que ver con la consecuencialidad lógica que con el azar. Las transgresiones que comete son varias, desde el ridículo cuidado de sus botas en medio de los yacarés al torpe uso del machete en inútil perjuicio de la vegetación. Toda su actitud se puede definir como la de un intruso en un lugar que merece respeto y temor, un intruso que no se da bien cuenta de dónde se encuentra. La selva, lugar de purificación, ya tiene para Quiroga un valor sagrado; y el intruso va adquiriendo cada vez más el carácter del profano y del sacrílego. La última transgresión de Benincasa es el robo de la miel y le costará la vida. Tampoco parece casual que las hormigas que se lo comen vivo se llamén 'corrección'." (CANFIELD, 1990, p.32)

\section{Consideraciones finales}

En estas narrativas analizadas fue posible percibir como el hombre interfiere en la vida de la floresta, como busca sacar provecho de ella y de qué forma ella reacciona. En "La miel silvestre", Benincasa, por gula, roba el producto más precioso de las abejas con la ilusión de que ellas no lo lastimarían, ya que no tenían aguilón. Además, por vestirse con botas muy resistente, también creía que las hormigas no le atacarían. Sin embargo, fueron ellas que lo devoraron. Lo mismo pasa con Subercasaux, que vive en la selva, sacando provecho de todo lo que está a su alcance, teniendo el mismo fin trágico de Benincasa.

De esta forma, podemos decir que animalitos como serpientes, garrapatas, piques, abejas, hormigas y tantos otros son enfocados por Quiroga en sus textos para resaltar de qué forma podemos ser disminuidos por ellos. No somos más poderosos, la capacidad tenemos, pero no se debería hacerlo y pasar a aprovecharnos de su espacio y de sus productos, como la miel y la leche vistos en los cuentos analizados. La selva no busca lastimar a los hombres. Lo que pasa es que su territorio es invadido y ella se siente amenazada. Para librarse, recurre a 
los animales para que la ayuden, vengándose de quien la explota.

"Tarántulas, serpientes gigantes o pequeñas pero con aterradoras toxinas, bandadas imparables de insaciables pirañas y hormigas carnívoras, ríos tan grandes y picados como mares atormentados y árboles antropomorfos que conspiran constantemente para extinguir del modo más doloroso posible la vida de todo organismo débil y/o invasor, son los actantes que la selva-muerte selecciona para encauzar sus formas hacia disposiciones y sensaciones similares a las logradas en géneros literarios fantásticos de terror u horror. La fatalidad en medio de la selva-muerte posee multiformes aspectos, en su gran mayoría desconocidos y por lo tanto productores del miedo, es por eso que este escenario selvático tropical resulta idóneo para incubar las configuraciones superlativas del miedo, tal y como se re-crean en la literatura." (RODRÍGUEZ, 2013, p.157)
DIEZ, Gustavo Pis; Enfermedad y literatura en Horacio Quiroga. Facultad de Medicina, UCM, Asclepio -Vol. LII-1-2000. Disponible en: http://docplayer.es/21631848-Enfermedad-yliteratura-en-horacio-quiroga-gustavo-pis-diez.html Acceso en 17 de noviembre de 2016

QUIROGA, Horacio; PONCE DE LEON, Napoleon Baccino; LAFFORGUE, Jorge. Todos los cuentos. 2. ed. Madrid: ALLCA XX, 1997.

RODRÍGUEZ, Miguel A. A.; Pasión selva y muerte en la obra de Horacio Quiroga y José Eustasio Rivera. Tesis de Maestría en Literatura, Pontificia Universidad Javeriana, Bogotá, 2013

WATTS, Allan; Naturaleza, hombre y mujer. Barcelona:Kairos, 1992.

\section{Referências}

CANFIELD, Martha; Horacio Quiroga: la selva sagrada y el reino perfectible. Revista de la Universidad Nacional (Abr-Jun); Vol. 6, Núm.24. 1990. Disponible en: http://www.revistas.unal.edu.co/index.php/revistau n/article/view/12210/12846 Acceso en: 17 de noviembre de 2016

CANFIELD, Martha; Verosimilitud y sacralidad de la selva. In:QUIROGA, Horacio; PONCE DE LEON, Napoleon Baccino; LAFFORGUE, Jorge. Todos los cuentos. 2. ed. Madrid: ALLCA XX, 1997.

Cuando el hombre es una bestia. Revista Pelo Pico Pata - № 49. Disponible en: http://deanimalia.com/articulos-cuando-el-hombrees-una-bestia.html acceso en 18 de noviembre de 2016

\section{COMO CITAR ESSE ARTIGO}

BATISTI, Bárbara Bianca; HENTGES, Cátia. LA INSIGNIFICANCIA DEL HOMBRE FRENTE A LOS ANIMALES EN LOS CUENTOS DE HORACIO QUIROGA. Signo, Santa Cruz do Sul, v. 43, n. 78, nov. 2018. ISSN 19822014. Disponível em: <https://online.unisc.br/seer/index.php/signo/article/view/11538>. Acesso em:__ doi: https://doi.org/10.17058/signo.v43i78.11538. 